\title{
ELECTRICAL MODELING OF SEMICONDUCTOR BRIDGE (SCB) BNCP DETONATORS WITH ELECTROCHEMICAL CAPACITOR FIRING SETS
}

\author{
K. D. Marx, D. Ingersoll, ${ }^{\dagger}$ and R. W. Bickes, Jr. ${ }^{\dagger}$ \\ Sandia National Laboratories \\ ${ }^{\dagger}$ Albucluerque, NM and ${ }^{\ddagger}$ Livermore, $C A$ \\ USA
}

\begin{abstract} OSTI

ABSTRACT

In this paper we describe computer models that simulate the electrical characteristics and hence, the firing characteristics and performance of a semiconductor bridge (SCB) detonator for the initiation of BNCP [tetraammine-cis-bis (5-nitro-2H-tetrazolato-N²) cobalt(III) perchlorate]. The electrical data and resultant models provide new insights into the fundamental behavior of SCB detonators, particularly with respect to the initiation mechanism and the interaction of the explosive powder with the SCB. One model developed, the Thermal Feedback Model, considers the total energy budget for the system, including the time evolution of the energy delivered to the powder by the electrical circuit, as well as that released by the ignition and subsequent chemical reaction of the powder. We also present data obtained using a new low-voltage firing set which employed an advanced electrochemical capacitor having a nominal capacitance of $350,000 \mu \mathrm{F}$ at $9 \mathrm{~V}$, the maximum voltage rating for this particular device. A model for this firing set and detonator was developed by making measurements of the intrinsic capacitance and equivalent series resistance (ESR $<10 \mathrm{~m} \Omega$ ) of a single device. This model was then used to predict the behavior of BNCP SCB detonators fired alone, as well as in a multishot, parallel-string configuration using a firing set composed of either a single $9 \mathrm{~V}$ electrochemical capacitor or two of the capacitors wired in series and charged to $18 \mathrm{~V}$.
\end{abstract}

RECEIVED JUN 021998

\section{INTRODUCTION}

Sandia research has demonstrated that semiconductor bridge (SCB) devices will operate under a wide range of operating conditions. ${ }^{1}$ Consequently, we believed that the development of an accurate detonator model and models for all the other electrical components in the associated firing systems would serve two main purposes. First, we could optimize the design of the explosive assembly (detonator and firing system) with a minimum of labora-

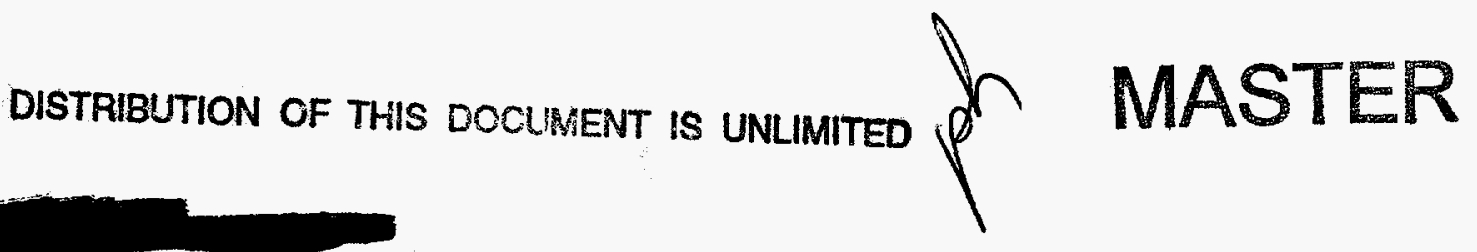




\section{DISCLAIMER}

This report was prepared as an account of work sponsored by an agency of the United States Government. Neither the United States Government nor any agency thereof, nor any of their employees, makes any warranty, express or implied, or assumes any legal liability or responsibility for the accuracy, completeness, or usefulness of any information, apparatus, product, or process disclosed, or represents that its use would not infringe privately owned rights. Reference herein to any specific commercial product, process, or service by trade name, trademark, manufacturer, or otherwise does not necessarily constitute or imply its endorsement, recommendation, or favoring by the United States Government or any agency thereof. The views and opinions of authors expressed herein do not necessarily state or reflect those of the United States Government or any agency thereof. 


\section{DISCLAIMER}

Portions of this document may be illegible in electronic image products. Images are produced from the best available original document. 
tory testing. And, second, we could estimate the effects on the explosive system of any deviations of the assembly components, for example those due to aging or temperature.

Our approach followed that employed for the models developed by Furnberg ${ }^{2}$ for exploding bridgewires (EBWs) and exploding foils. The basis of Furnberg's models is a description of the detonator resistance as a function of energy. We augmented that approach by including empirical descriptions of the SCB energy loss and the feedback of thermal energy from the explosive powder to the SCB. The work presented here is, in part, a summary of a more detailed report by Marx et al. ${ }^{3}$

The detonator models described here consist of a mathematical and computational specification of the electrical behavior of the detonator which is independent of the simulation software. However, we exclusively used the PSpice ${ }^{\circledast}$ computer program by MicroSim Corporation.

\section{SE:MICONDUCTOR BRIDGE}

The operating principles of SCBs and their applications in explosive devices are discussed in Benson et al., ${ }^{4}$ Bickes et al., ${ }^{5}$ and Martinez-Tovar. ${ }^{6}$ Passage of a current pulse through the SCB causes it to burst into a plasma discharge that heats the exoergic powder pressed against it by a process that is both rapid and efficient. Consequently SCB devices operate at low energies and function very quickly. But despite the low energy for ignition (a factor ten less than for hot-wire actuators ${ }^{5}$ ), the SCB substrate provides a reliable heat sink for excellent no-fire levels.

Figure 1 shows the detonator used for the experiments in this paper. SCB chips were mounted on transistor headers; the charge holder was a brass cylinder loaded with $75 \mathrm{mg}$ of $\mathrm{BNCP}^{\dagger}$ pressed against the SCB to 20,000 psi.

${ }^{\dagger}$ Tetraammine-cis-bis (5-nitro-2H-tetrazolato- $\mathrm{N}^{2}$ ) cobalt(III) perchlorate, processed by Pacific Scientific, Chandler, AZ. 


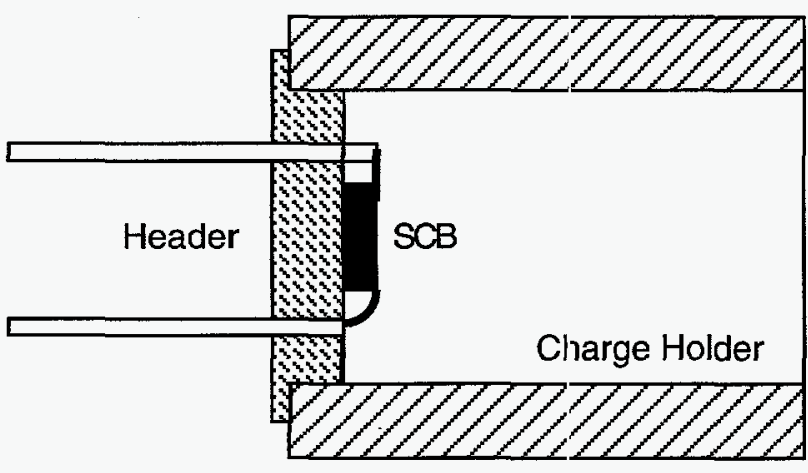

Figure 1. The detonator header is a standard TO-46 transistor base. The brass charge holder has an internal diameter of $0.015 "(3.8 \mathrm{~mm})$ and an internal length of $0.270 "(6.9 \mathrm{~mm})$. The outside diameter is $0.25 "(6.9 \mathrm{~mm})$.
The detonator was connected to a low-voltage capacitive discharge unit (CDU) firing set which contained a silicon controlled rectifier (SCR) switch (see Figure 2). The electrical data obtained (SCB voltage and current waveforms) provided some new insights into the way SCBs operate in a BNCP detonator. In particular, we will show that there is an important interaction

between the BNCP powder and the SCB which must be included in the electrical model of the detonator. Tests of SCBs fired in air and into various explosive powders showed that the electrical behavior is dependent on the presence or absence of the powder and the type of powder used. This paper is restricted to BNCP, and we anticipate that models for other exoergic materials may differ.

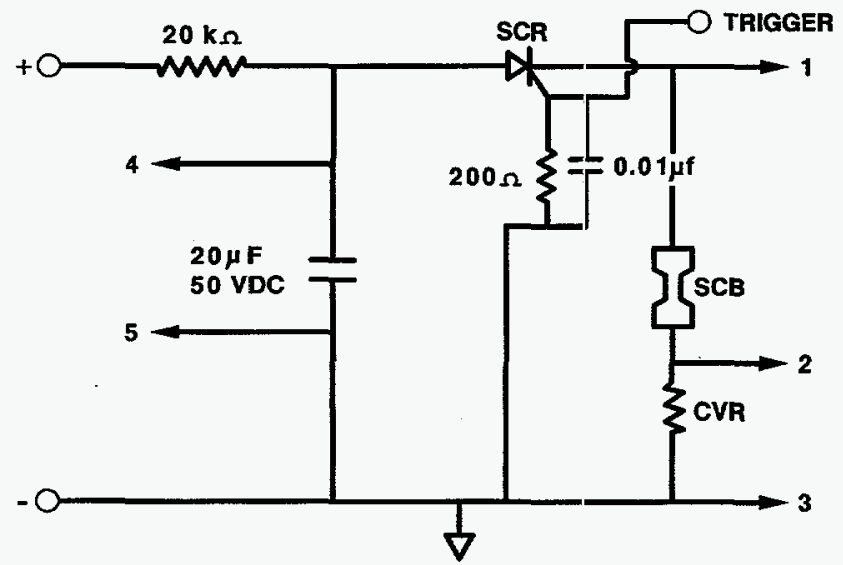

Figure 2. Firing set used for experiments. Voltage data was taken from a $50 \Omega$ instrumentation line between points 1 and 3 and current data from $a$ similar line connected between Points 2 and 3 . The current viewing resistor $(C V R)$ was $\approx 10 \mathrm{~m} \Omega$. The capacitor size and charge voltage (monitored across points 4 and 5) was varied for the tests.

\section{SIMPLE MODEL}

Data from a typical SCB shot are shown in Figure 3. The firing set used for this test employed a $19.08 \mu \mathrm{F}$ capacitor charged to $50 \mathrm{~V}$. The sudden drop in current at $1.6 \mu \mathrm{s}$ corresponds to vaporization of the bridge, and the time at which this occurs is denoted as burst time in the figure. Vaporization of the bridge is required to obtain ignition of the powder pressed against the SCB. At very early times the resistance plotted in the figure is very large; this is due to inductance in the circuit and is an initial transient that always appears - it is not the true resistance. 


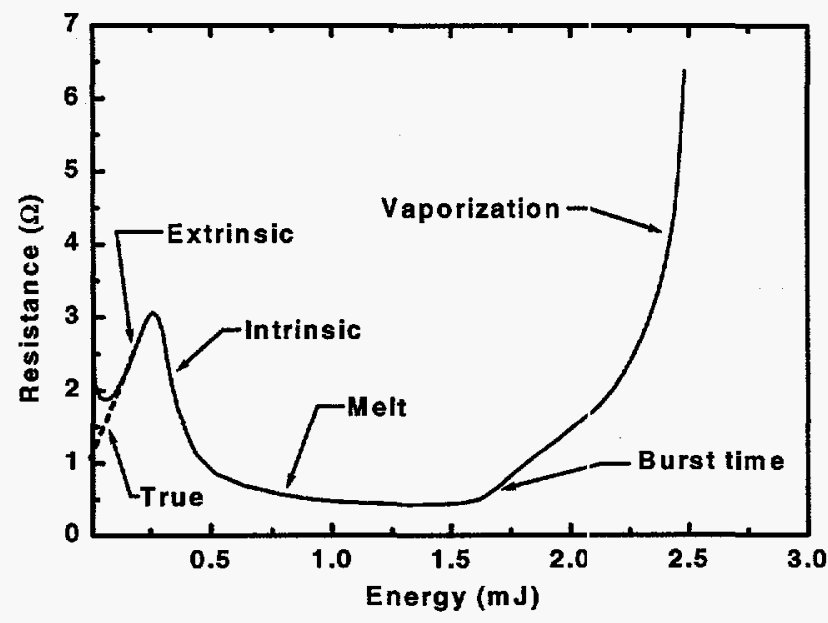

Figure 3. Resistance vs. Energy from the data in Figure 3.
The resistance versus energy plot resulting from the data in Figure 3 is shown in Figure 4. The bridge proceeds through several stages as the current pulse is applied. First is the extrinsic conduction stage when the doped silicon exhibits a positive temperature coefficient of resistivity; second is the intrinsic conduction stage when the bridge temperature is raised sufficiently to release a large number of charge carriers, and the temperature coefficient becomes negative; third is when the bridge melts; and the fourth occurs when the resistivity of the bridge increases rapidly due to the vaporization of the silicon (burst). The enthalpy required to completely vaporize the silicon in the bridge was calculated to be $1.65 \mathrm{~mJ}$. The dashed line in the figure denotes the "true" resistance behavior; all of the SCBs tested had a nominal ambient resistance of $1 \Omega$.

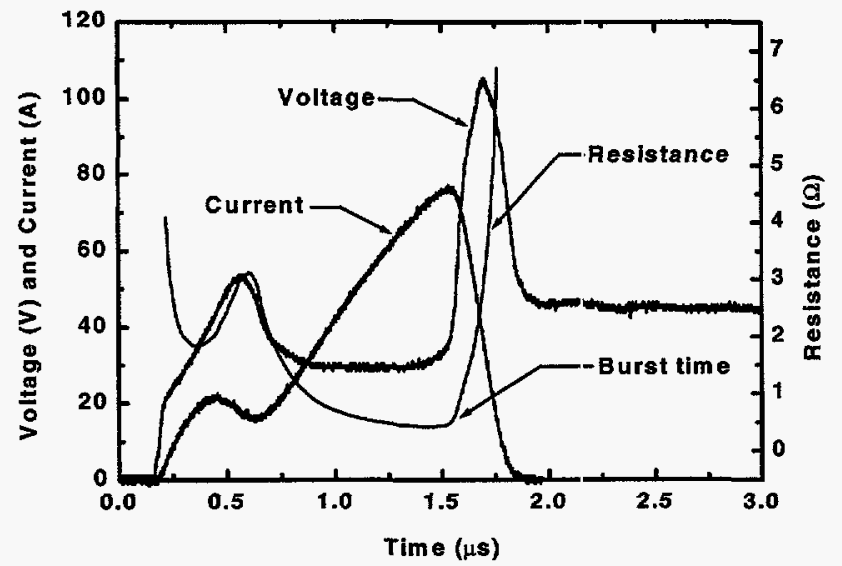

Figure 4. Data from Shot 1318 illustrating typical $S C B$ behavior. Raw data are shown for the voltage and current; however, the resistance is obtained from filtered voltage and current signals.
Because the behavior of the SCB resistance is complicated, we used a look-up procedure in PSpice ${ }^{\circledast}$ to model the SCB resistance as a function of energy. The process for obtaining a simple model for an SCB from the data in Figures 3 and 4 is as follows. (1) Obtain a spline fit of the $R$ vs. E data. (2) Create a table of $R$ and $\mathrm{E}$ values from the fit. (3) Create a PSpice ${ }^{\circledast}$ part which is an analog behavioral model having the $\mathrm{R}$ vs. $\mathrm{E}$ characteristics given by the table. 


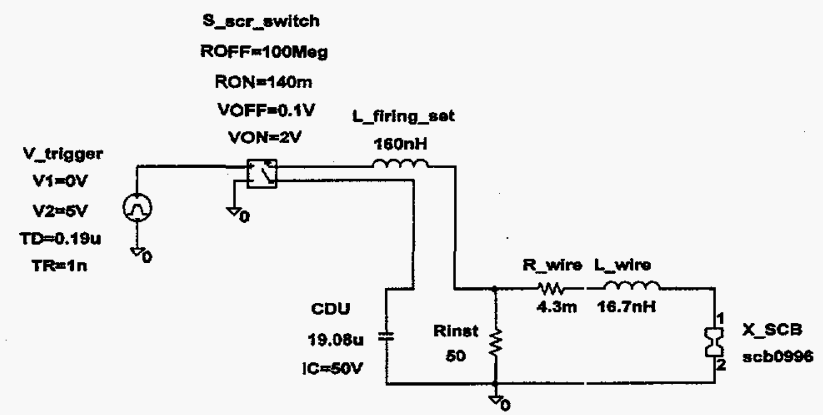

Figure 5. PSpice ${ }^{\circledR}$ model for the circuit used to obtain $S C B$ data. The CVR used to obtain current data (see Figure 2) was not included in the circuit.
The PSpice ${ }^{\circledast}$ schematic of the circuit we used to simulate the SCB tests is shown in Figure 5. The resistance $R \_$wire (4.3 $\mathrm{m} \Omega$ ) and inductance $L \_$wire $(16.7 \mathrm{nH})$ shown in the figure are estimates for the lines connecting the SCB detonator to the firing set. Figure 6 gives the results of simulating four different detonator tests with the simple model.

The data for shot 1318 was used. to derive the model and hence shows good agreement with experiment. The voltage spike at burst depends very little on the model and is dominated by the inductance of the firing set ( $L$ firing _set in Figure 5).
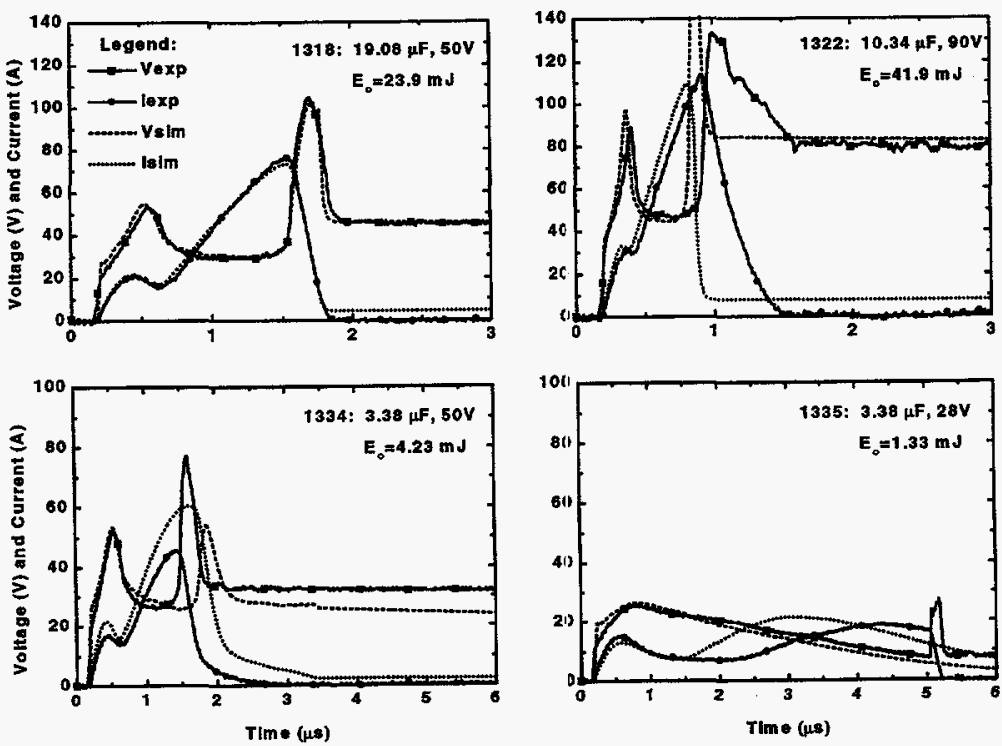

Note different time and amplitude scales

Figure 6. Results of applying the simple model to selected shots that vary widely in energy initially stored on the firing set capacitor. Shot 1318 is in the intermediate energy range; shot 1322 is in the high energy range, ond shots 1334 and 1335 are in the low energy range.
Shot 1322 used a $10.34 \mu \mathrm{F}$ capacitor charged to $90 \mathrm{~V}$; the stored energy $(41.9 \mathrm{~mJ})$ is much more than needed to burst the bridge. While the burst time predicted by the simple model is close to the experimental result, the voltage spike is much too large. Shot 1334 used a $3.38 \mu \mathrm{F}$ capacitor charged to $50 \mathrm{~V}$; here the stored energy in the circuit is just two to three times more than that needed to burst the bridge. The predicted burst time is close to experiment; how- 
ever, we believe this is the lower range of energy for which the model is useful. Shot 1335 used a $3.38 \mu \mathrm{F}$ capacitor charged to $28 \mathrm{~V}$; the stored energy is $1.33 \mathrm{~mJ}$, which is less than the theoretical value $(1.65 \mathrm{~mJ})$ required to burst the bridge. Consequently, the model predicts that the bridge will not burst; this is in contrast to the experiment which showed the bridge burst at about $5 \mu \mathrm{s}$. This important result is indicative of a thermal feedback from the ignition and burning of the BNCP into the SCB causing it to burst.

\section{MODELING OVER A BROAD RANGE OF ENERGIES}

\section{High Energy Regime - The Lossy Model}

The simple model did not yield accurate results over a wide range of firing set energies. In Figure 7 we show the $R$ vs. E curves for a large number of shots for which the detonator

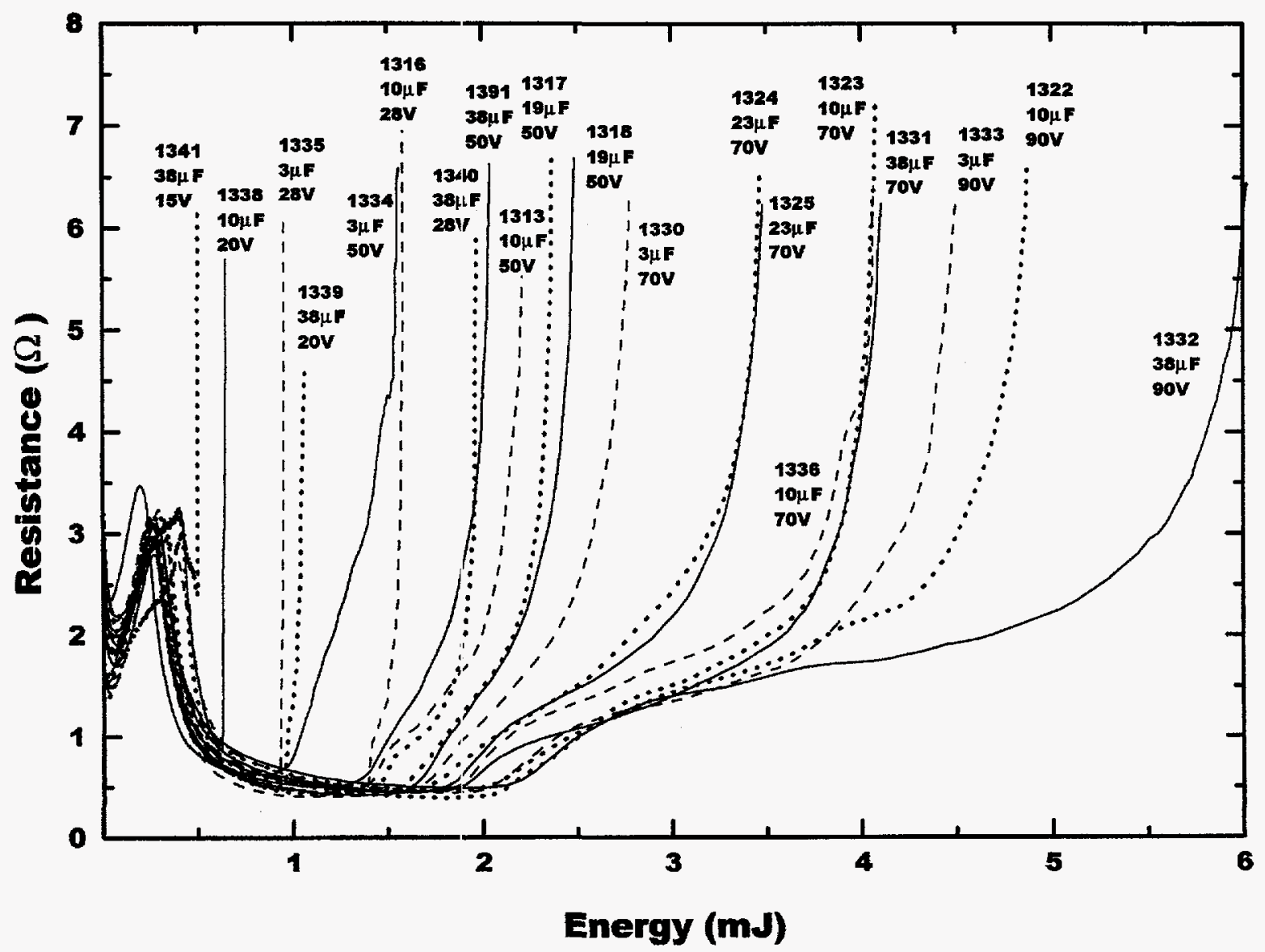

Figure 7. Resistance vs. energy for a variety of CDU capacitances and initial voltages. The legends indicate shot numbers, CDU capacitance and charge voltage. Some shot conditions were repeated to investigate shot-to-shot variation (shot pairs 1317/1318, 1323/1324 and $1323 / 1336$ ). 
fired. It is clear that the resistance is not a unique function of the energy. The data tend to fall into three groups. (1) High-energy shots for which the resistance rises fairly slowly with increasing energy after the initial rise and fall in resistance. (2) Low-energy shots for which the resistance makes a sudden rapid jump at burst. (3) Intermediate-energy shots which comprise a transition region between the other two but exhibit behavior similar to the high energy. These three groupings apply not only to the electrical energy delivered to the SCB but also to the initial CDU stored energy.

With regard to the high energy data, the energy to burst tends to increase as the initial voltage on the CDU is increased because there is a stretching out of the energy required to burst the SCB. We believe this behavior results from an energy loss mechanism including ohmic losses in the leads and lands as well as heat transfer from the SCB to the substrate and to the explosive powder. We decided that the most straightforward approach was to assume that the loss was a function of the instantaneous voltage $\mathrm{V}$ at the SCB leads given by

$$
\frac{d E_{S C B}}{d t}=V I\left[1-A_{L} f_{L}(V)\right]
$$

$\mathrm{E}_{\mathrm{SCB}}$ is the instantaneous energy contained in the bridge itself; $f_{L}(V)$ is a function of instantaneous SCB voltage; $A_{L}$ is a multiplicative constant used to adjust the amplitude of the loss. Since our data offer no way to determine if the loss mechanism exists at low voltages, we chose a function that is zero at low voltages and increases as a function of voltage past some threshold which was chosen as $35 \mathrm{~V}$, see Figure 8.

We adjusted $A_{L}$ so as to obtain the best fit to the data from a high energy shot for which the firing set capacitance was $10.34 \mu \mathrm{F}$ and the CDU voltage was $90 \mathrm{~V}$ (shot 1322). These parameters represent the nominal capacitance but the maximum voltage anticipated for some applications. We found that $A_{L}=0.3$ gave a good fit to the data for shot 1322 . The results are shown in Figure 9 and are to be compared to Figure 6.

There is very little difference between the high-energy loss model and the simple model for shot 1334 because the loss term has little effect. For shot 1335 there is no difference because the voltage did not reach $35 \mathrm{~V}$. The behavior of the model after burst for shot 1318 is somewhat deteriorated after burst. The behavior of the lossy model for shots 1334 and 1318 is similar — the burst times 


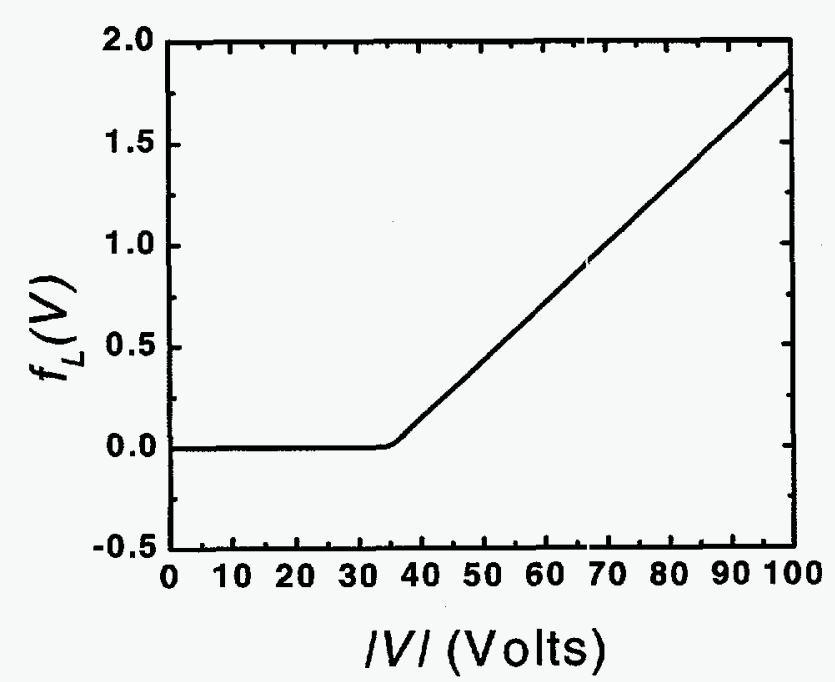

Figure 8. The function $f L(V)$ of $S C B$ voltage used in the energy loss model. Note that the absolute value of voltage is used, so that the model does not depend on polarity. are greater than the experimental values and the voltage spikes are reduced.

\section{Low-Energy Regime - The Thermal Feedback Model}

As noted, the detonators will fire even though the initial energy stored on the CDU is less than the energy required to completely vaporize the SCB. Another feature of the low-energy data is that, while the SCBs take longer to burst as the energy and voltage on the CDU are decreased, they burst very suddenly when they do burst. A reasonable ex-

planation $^{7}$ for these characteristics is that as the SCB heats up the BNCP which ignites and burns, feeding energy back into the SCB and completing the vaporization and burst process in the bridge.
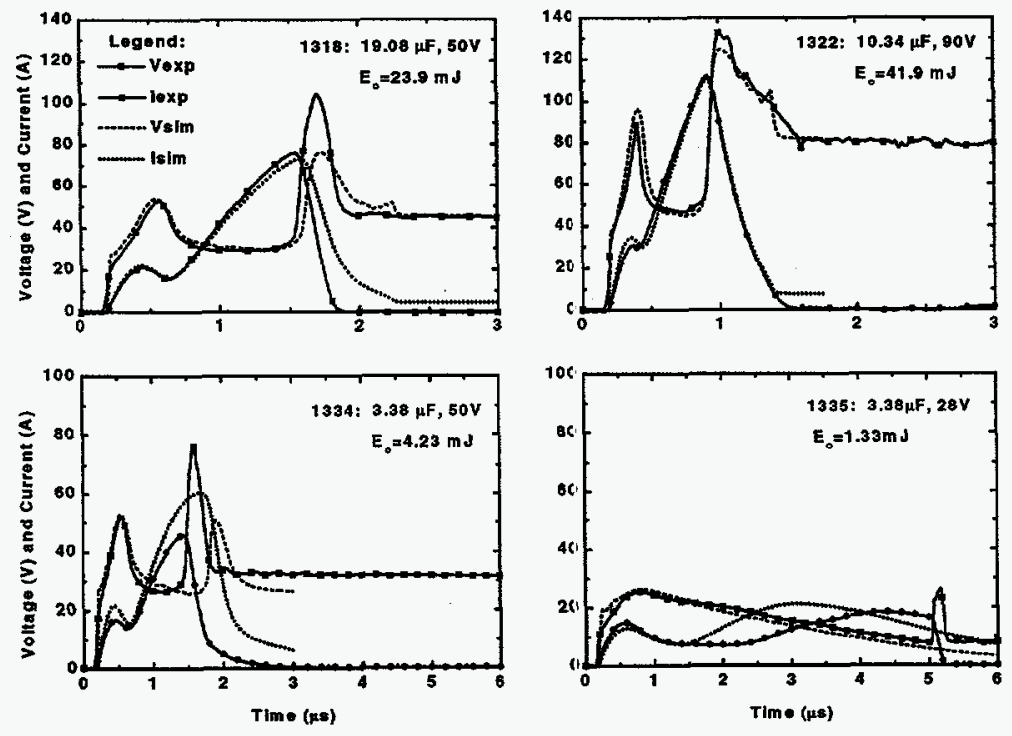

Note different time and amplitude scales

Figure 9. Results of applying the SCB model with the high-energy loss term to selected shots. Compare these plots using the lossy model to those in Figure 6 using the simple model
We developed a model based on this supposition which is described in detail in Reference 3 . This model has the form $\frac{d E_{S C B}}{d t}=V I\left[1-A_{L} f_{L}(V)\right]+\left[\dot{E}_{S C B}\right]_{I F}$ where the last term is the thermal feedback heat transfer rate back into the SCB. The $R$ vs. E look-up table from Shot 1318, used for the previous models, did not give good results when applied 
with Eq. (2) to the low-energy shots. This problem was solved by creating a new $\mathrm{R}$ vs. $\mathrm{E}$ table from three shots that ranged in energy from very low to the mid-range of our studies (shots 1338, 1316, 1318). The new table followed the data from 1338 at first, switched to 1316 and then to 1318.

Figure 10 shows simulations using the thermal feedback model. The agreement
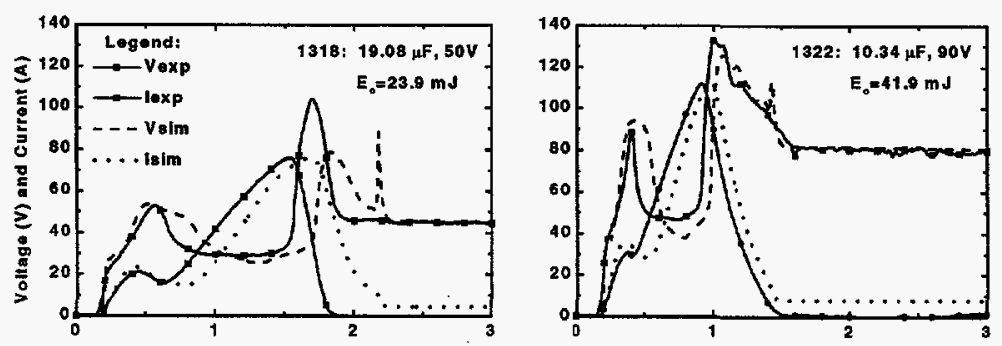

between simulation and ex-
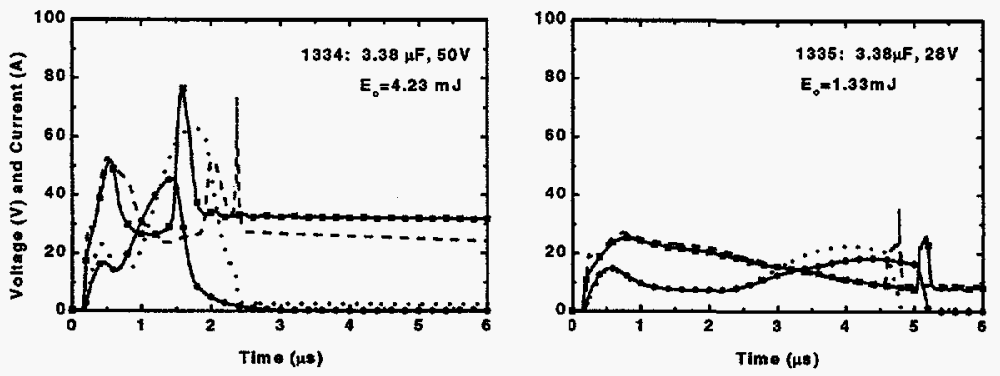

Note different time and ainplitude scales

Figure 10. Results of simulations using the thermal feedback $S C B$ model (dashed lines) periment in the intermediate and high-energy regimes is not quite as good as for the model in which thermal feed back was omitted. The reason is that the new $R$ vs. $E$ table does not match the experimental data as well as that obtained from shot 1318 alone. Still, for high-energy shots, the simulation results depend more on the details of the high-energy portion of the resistance versus energy characteristics than on the low-energy regime. Conversely, simulation of the low-energy shots requires accurate representation of the low-energy regime. Hence, the model which combines thermal feedback with the nonlinear energy loss does a good job over the entire data range.

\section{ELECTROCHEMICAL CAPACITOR STUDIES}

Electrochemical capacitors are in many respects similar to the more familiar dielectric and electrolytic capacitors. However, one of the primary differences between these devices is in the amount of charge that can be stored in an electrochemical capacitor as compared to either a dielectric or electrolytic capacitor. In fact, for similar sized devices, the electrochemical capacitor is capable of storing orders of magnitude more charge than either of the 
other types of capacitors. This charge is generally stored at a lower voltage due to the breakdown characteristics of the ionically conductive medium separating the two electrodes. Typical individual cell operating voltages are on the order of $1 \mathrm{~V}$ to $3 \mathrm{~V}$. Therefore, in order obtain higher operating voltages, several cells must be connected in series; this can be done in a single package.

Two devices were used in this work. One is a $9 \mathrm{~V}$ device having a capacitance of $650,000 \mu \mathrm{F}$, and the other was a $35 \mathrm{~V}$ device with a capacitance of $130,000 \mu \mathrm{F}$. The physical dimensions of the $9 \mathrm{~V}$ prismatic device are $39 \mathrm{~mm}$ by $65 \mathrm{~mm}$ by $5 \mathrm{~mm}$ thick, illustrating the relatively small size of the device. The $35 \mathrm{~V}$ device has a thickness of $11 \mathrm{~mm}$, with all of the other dimensions remaining the same as the $9 \mathrm{~V}$ device.

From a modeling standpoint these devices can be represented by an RC network with at least three time constants. In this case, the different portions of the network with the different time constants correspond to the relative response rates of the charge and discharge process which in turn correspond to the different physical and chemical processes occurring during this time. For the work performed here, an even simpler representation consisting of a series configuration of a single capacitor and single resistor can be used, with the equivalent series resistance, ESR, of the device being used for the value of the resistor. In these devices the ESR is a function of the surface area of the electrode, and is approximately $10 \mathrm{~m} \Omega$.

In our first tests we fired SCBs in air using a $650,000 \mu \mathrm{F}$ capacitor charged to $9 \mathrm{~V}$. In this case, because of the low rate of energy deposition into the bridge, the bridge did not burst until $4.7 \mathrm{~ms}$ after the onset of the current pulse. This is in contrast to the microsecond response predicted by the model and observed experimentally for a BNCP detonator. In fact, in tests with the BNCP detonators function times of 23 and $33 \mu \mathrm{s}$ were found, in good agreement with the simulation results. These tests clearly illustrate the effect of the thermal feedback mechanism, since for the shots in air no additional energy was supplied to the SCB through the combustion process of the powder. At a charge voltage of $18 \mathrm{~V}$, the detonator functioned in $8 \mu \mathrm{s}$. 
We assembled a multishot, parallel-string configuration using two of the $350,000 \mu \mathrm{F}$ capacitors in series and charged to $18 \mathrm{~V}$ in order to further evaluate the electrochemical capacitors and model simulations. In this case nine detonators were connected in parallel and two SCR switches, also connected in parallel, were used to fire the SCBs. The SCR switches were wired in parallel because the ESR of the circuit was dominated by the ESR of the switch, and a significant fraction of the load was dropped across a single SCR. The function times for the nine detonators ranged from $54.5 \mu \mathrm{s}$ to $70.1 \mu \mathrm{s}$ (average time of $63.4 \mu \mathrm{s}$ and a sigma of $6 \mu \mathrm{s})$. Through the use of the modeling, in combination with the test results, it was determined that the variability in the firing times of the SCBs could be accounted for by the initial variability in the ESR of the loaded SCBs. Although these differences were small, they were enough to affect the firing times.

A second multishot test with a $130,000 \mu \mathrm{F}$ capacitor charged to $35 \mathrm{~V}$ and 10 detonators had function times that ranged from $7.9 \mu \mathrm{s}$ to $12.6 \mu \mathrm{s}$ (average time of $8.9 \mu \mathrm{s}$ and a sigma of $1.3 \mu \mathrm{s})$. Simulations were performed for circuits employing more than 80 detonators in parallel from a single firing set, and these results indicated that sufficient energy is available in the electrochemical capacitor to fire the SCBs simultaneously. We expect that even more SCBs could be fired using this circuit; however, based on the time required for simulating the 80 shot test ( $3 \mathrm{hrs}$ on a $60 \mathrm{MHz}$ machine), additional simulations were not performed. But, based on the nine-shot experiment and simulation, the ESR of the switch is expected to be the controlling element in the firing set circuit.

\section{SUMMARY}

Our data show that SCB/BCNP detonators can be electrically characterized by assuming that their dynamic resistance is a function of the energy deposited in the bridge after accounting for an energy loss and the feedback of thermal energy from the burning explosive powder. We did not identify the sources of the energy loss but believe it to be a nonlinear function of the voltage across the SCB at higher voltage levels of operation. The thermal feedback mechanism is nost important at the lower levels of CDU stored energy.

Our recommendation is to use the lossy model without thermal feedback for simulations of detonator systems for which operation is clearly in the higher energy range. But the 
thermal feedback model should be employed in any simulation in which the energy supplied to the detonator is considered to be marginally sufficient for firing.

Our models were developed for a capacitance range of $3.4 \mu \mathrm{F}$ to $19.1 \mu \mathrm{F}$ and charge voltage ranging form $15 \mathrm{~V}$ to $90 \mathrm{~V}$. Nonetheless, the thermal feedback model successfully simulated detonator performance for firing sets with capacitances ranging from $130,000 \mu \mathrm{F}$ to $350,000 \mu \mathrm{F}$ at charge voltages from 9 to $35 \mathrm{~V}$. We consider these results quite remarkable. In addition, we demonstrated that these electrothermal capacitors could be used to fire tens of detonators simultaneously.

\section{ACKNOWLEDGMENTS}

This work was supported by the United States Department of Energy under Contract DEAC04-94AL85000. Sandia is a multiprogram laboratory operated by Sandia Corporation, a Lockheed Martin Company, for the United States Department of Energy. Our thanks to Dave Wackerbarth for his expertise in the laboratory.

\section{REFERENCES}

${ }^{1}$ See, for example, R. W. Bickes, Jr. M.C. Grubelich, S. M. Harris, J. H. Weinlein, "An Overview of Semiconductor Bridge, SCB, Applications at Sandia National Laboratories," $31^{\text {st }}$ AIAA/ASME/SAE/ASEE Joint Propulsion Conference and Exhibit, American Institute of Aeronautics and Astronautics, San Diego, CA (July 10-12, 1995).

${ }^{2}$ C. M. Furnberg, "Computer Modeling of Detonators," IEEE $37^{\text {th }}$ Conference on Circuits and Systems, Lafayette, LA (Aug. 3-5, 1994).

${ }^{3}$ K. D. Marx, R. W. Bickes, Jr. and D. E. Wackerbarth, "Characterization and Electrical Modeling of Semiconductor Bridges," Sandia National Laboratories Report SAND97-8246 (March 1997).

${ }^{4}$ D. A. Benson, M. E. Larsen, A. M. Renlund, W. M. Trott, and R. W. Bickes, Jr. "Semiconductor bridge: A plasma generator for the ignition of explosives," Journ. Appl. Phys. 62 (5), 1662 (1987).

${ }^{5}$ R. W. Bickes, Jr., W. L. Schlobohm and D. W. Ewick, "Semiconductor Bridge (SCB) Igniter Studies: I. Comparison of SCB and Hot-Wire Pyrotechnic Actuators," $13^{\text {th }}$ International Pyrotechnics Seminar, Grand Junction, CO (July 11-15, 1988).

${ }^{6}$ B. Martinez-Tovar, "Electrothermal Transients in Highly Doped Phosphorous Diffused Silicon-onSapphire Semiconductor Bridges (SCB) Under High Current Density Conditions," Ph.D. Dissertation, The University of New Mexico, Albuquerque, NM (July 1993).

${ }^{7}$ K. C. Jungling, University of New Mexico, private communication (1996). 